\title{
Oral topical doxepin rinse: Anesthetic effect in normal subjects
}

\author{
Joel B Epstein DMD MSD FRCDC ${ }^{1}$, Edmond L Truelove DDS MSD², Hal Oien DDS 3 , \\ Nhu D Le PhD ${ }^{4}$, Mathew S Epstein ${ }^{5}$
}

\begin{abstract}
JB Epstein, EL Truelove, H Oien, ND Le, MS Epstein. Oral topical doxepin rinse: Anesthetic effect in normal subjects. Pain Res Manage 2003;8(4):195-197.
\end{abstract}

Oral doxepin rinse has been reported to provide pain relief in patients with oral mucosal lesions due to cancer or cancer therapy. The purpose of this study was to assess the anesthetic effect of doxepin oral rinse in normal subjects to identify the duration of effect and to contrast the anesthetic effect with reported pain relief in patients with oral mucosal lesions.

Normal volunteers were provided a solution of doxepin $(5 \mathrm{mg} / \mathrm{mL})$ for oral rinsing. Oral numbness and adverse effects were recorded for a period of $4 \mathrm{~h}$ after rinsing.

Doxepin rinse resulted in mucosal anesthesia in all subjects. Sedation/fatigue was reported in four of seven subjects. There were no taste complaints and no nausea reported.

The limited duration of numbness/anesthesia in normal subjects compared with prior studies showing pain relief for more than $3 \mathrm{~h}$ in patients with mucosal lesions, suggests that the extended duration of pain relief in patients was due to analgesic effects rather than anesthetic effects. The majority of normal subjects reported sedation after use, but this was less common in patients with mucosal lesions.

\section{Un rince-bouche de doxépine topique : L'effet anesthésique chez les sujets en santé}

Il a été déclaré que le rince-bouche de doxépine soulage la douleur des patients ayant des lésions muqueuses orales causées par le cancer ou le traitement du cancer. La présente étude vise à évaluer l'effet anesthésique du rince-bouche de doxépine chez des sujets en santé afin d'établir la durée de l'effet et de contraster l'effet anesthésique au soulagement déclaré de la douleur de patients ayant des lésions muqueuses orales.

Des volontaires en santé ont reçu une solution de doxépine $(5 \mathrm{mg} / \mathrm{mL})$ afin de se rincer la bouche. L'engourdissement oral et les effets secondaires ont été inscrits pendant une période de quatre heures après l'utilisation. Le rince-bouche de doxépine a entrainé l'anesthésie muqueuse de tous les sujets. Quatre des sept patients ont déclaré un effet de sédation ou une lassitude. Personne ne s'est plaint du goût ou de nausées.

La durée limitée de l'engourdissement et de l'anesthésie des sujets en santé, par rapport aux études antérieures faisant état d'un soulagement de la douleur pendant plus de trois heures chez les patients présentant des lésions muqueuses, laisse supposer que la longue période de soulagement des patients était imputable aux effets analgésiques plutôt qu'aux effets anesthésiques. La majorité des sujets normaux ont rendu compte d'une sédation après l'usage, mais cette sensation était moins courante chez les patients ayant des lésions muqueuses.

Key Words: Doxepin; Topical analgesia; Topical anesthetic

$\mathrm{D}$ oxepin $\left(\mathrm{C}_{19} \mathrm{H}_{21} \mathrm{~N} . \mathrm{HCl}\right)$ is a tricyclic antidepressant (TCA) drug. Tricyclics appear to have both central and peripheral effects. The primary mechanism of action may be on descending pathways by blocking reuptake of serotonin and norepinephrine $(1,2)$. Doxepin has potent $\mathrm{H} 1$ and $\mathrm{H} 2$ receptor blocking activity. In addition, nonspecific enkephalin-like activity has been demonstrated in patients who were prescribed doxepin (3). TCAs may also affect $n$-methyl-d-aspartate receptors in addition to effects on the descending norepinephrine and serotonergic systems (4). Once systemically absorbed, doxepin is converted in the liver to desmethyldoxepin, an active metabolite, which is excreted in the urine following glucuronidation (2). Plasma levels of drug and metabolite are highly variable, and correlate with variable absorption following systemic administration.

Doxepin is used in the management of depression and chronic pain $(1,3,5-8)$. Systemic use leads to sleep facilitation, and reduced pain (1). Tricyclics have analgesic effects in neuropathic pain, independent of their antidepressant effect $(1,5,6)$. Doxepin has been used in combination with nonsteroidal anti-inflammatory drugs in the management of pain associated with advanced cancer (7). Systemic doxepin has also been used in pain management associated with oral mucositis (8). Systemic doxepin, when used for treatment of depression, produces drowsiness in a significant number of patients. Doxepin is contraindicated in patients with narrow angle glaucoma, and for patients with urinary retention. Serious drug interactions may occur when used with monoamine oxidase inhibitors. There is no evidence in animal studies of teratogenic effects (2), and no studies of use during pregnancy have been reported.

Topical application of doxepin has been prescribed for the management of skin pruritus $(5,9)$ and for neuropathic pain of the skin $(5,10)$. We have previously reported pain relief following

\footnotetext{
${ }^{1}$ Medical-Dental Staff, British Columbia Cancer Agency, Vancouver, British Columbia; Department of Oral Medicine and Diagnostic Sciences, College of Dentistry, University of Illinois, Chicago, Illinois, USA; ${ }^{2}$ Department of Oral Medicine, University of Washington, Seattle,

Washington, USA; ${ }^{3}$ Beaverton, Oregon, USA; ${ }^{4}$ Cancer Control Research, British Columbia Cancer Agency, Vancouver, British Columbia;

${ }^{5}$ Fred Hutchinson Cancer Research Center, Seattle, Washington, USA

Correspondence: Dr Joel B Epstein, Department of Oral Medicine and Diagnostic Sciences, MC 838, 801 S Paulina Street, Chicago, Illinois 60612 USA. Telephone 312-996-7480, fax 312-335-2688, e-mail jepstein@uic.edu
} 
oral rinsing with doxepin suspension in patients with oral lesions due to cancer or treatment of cancer (11). The purpose of the present study was to assess the anesthetic effect of doxepin in patients with intact mucosa, and to compare the duration of effect with the previously reported reduction in oral pain in cancer patients.

\section{MATERIALS AND METHODS}

The present study was a single dose, open label trial of an oral rinse of doxepin suspension. Normal subjects volunteered for a single oral rinse application. Doxepin suspension was prepared at $5 \mathrm{mg} / \mathrm{mL}$ in an oral rinse containing $0.1 \%$ alcohol and sorbitol. Subjects rinsed $5 \mathrm{~mL}$ for $1 \mathrm{~min}$ and spit out. Subjects completed Visual Analogue Scales (VAS) to assess pain and side effects following the use of the rinse at $5 \mathrm{~min}, 15 \mathrm{~min}, 30 \mathrm{~min}, 1 \mathrm{~h}$ and continuing every $0.5 \mathrm{~h}$ up to $4 \mathrm{~h}$. Subjects evaluated their appraisal of taste, stinging (or burning) with use of the rinse, numbness (anesthesia), and drowsiness or fatigue following rinsing. The VAS taste measure used anchors of $0=$ terrible, $5=$ acceptable and $10=$ excellent. Fatigue following use was reported on a VAS scale with $0=$ none and $10=$ severe, leading to sleep.

Statistical analyses were performed using S-Plus 4.0 release 3 for Windows (MatSoft Inc, USA). The nonparametric Wilcoxon signed rank test, was used to assess the outcome measures.

\section{RESULTS}

Seven volunteers (four women and three men) participated. The mean age was 38.7 years (range 18 to 50 years). No oral mucosal lesions and no mouth pain were present. No anesthetics and no analgesic use was reported in the $72 \mathrm{~h}$ prior.

No discomfort or stinging was reported by any participant during or following rinsing. The taste was reported to be good to excellent (VAS mean 8/10; range 6 to 10 ). The VAS pain and drowsiness/fatigue results are shown in Table 1.

\section{DISCUSSION}

This trial assessed subjective anesthesia in patients with intact mucosa, without mucosal sensitivity. Analgesia could not be assessed because no pain was present. In subjects with intact mucosa, self report of anesthesia began by $5 \mathrm{~min}$, and reached a maximum in $15 \mathrm{~min}$ to $30 \mathrm{~min}$, with a rapid return to normal after $1 \mathrm{~h}$ and resolution by $1.5 \mathrm{~h}$ to $2 \mathrm{~h}$. The reported duration of anesthesia in this trial is similar to, but longer than that reported in prior studies of topical anesthetic agents, which usually is less than $0.5 \mathrm{~h}(12,13)$. While topical anesthetics typically cause burning sensitivity when applied to damaged mucosa, this was not reported in the prior study with cancer patients (11). Topical anesthetics may also reduce or eliminate the gag reflex, and taste and sensation with eating and swallowing. Systemic absorption of topical anesthetics may cause cardiac effects (1416). Burning sensitivity or stinging has not been reported in our prior study of topical doxepin rinse in cancer patients with oral mucosal lesions (11).

Fatigue/drowsiness was a common complaint, developing in more than one-half of the subjects, with moderate to high ratings in those who reported fatigue. Maximum fatigue ratings were severe, but an average rating of moderate fatigue was reported. Fatigue was reported later than the anesthetic effect, suggesting a local action resulting in anesthesia and a central action resulting in fatigue. Topical doxepin applied to the skin in areas of neuropathic pain has been shown to have good analgesic effect $(9,10,17)$. Drowsiness has been reported following skin application (5).

In our earlier report, the intensity and duration of pain reduction was assessed in cancer patients with symptomatic oral mucosal lesions (11). The previous study showed that the analgesic effect resulted in a reduction of pain intensity of more than $50 \%$, with greatest relief after $1 \mathrm{~h}$ to $2 \mathrm{~h}$ with a duration of more than $3 \mathrm{~h}$, and pain not returning to baseline at $4 \mathrm{~h}$ after rinsing. The rinse was reported to have an acceptable taste and infrequent stinging with use. In the present normal volunteer study, there was no pain at baseline, but a sensation of numbness following rinsing resolved rapidly, suggesting that pain relief reported in the previous study of cancer patients was likely due to an early anesthetic effect, and a return to normal sensation with persisting pain relief was due to an analgesic effect with a duration of approximately $4 \mathrm{~h}$. In the normal volunteer study, fatigue developed later than the anesthetic effect and was a more common complaint than in the cancer patients. Pain reduction in cancer patients appears to be related to both local anesthetic and analgesic effects, and fatigue likely represents a central effect. The effect upon pain in mucositis may also be related to prolonged local anesthesia leading to reduction in neurologic 'windup' that may occur in prolonged pain.

These findings suggest a relatively short period of anesthesia and an extended period of analgesia following use of doxepin oral rinse. In addition, the greater report of fatigue in normal volunteers suggests that further dose ranging studies are indicated. It is

\section{TABLE 1}

Subject reports of symptoms following doxepin oral rinse

\begin{tabular}{|c|c|c|c|c|c|c|}
\hline Time post rinse & $\begin{array}{c}\text { Oral numbness } \\
\text { VAS }\end{array}$ & Mean & $\mathbf{P}^{*}$ & $\begin{array}{c}\text { Drowsiness/fatigue } \\
\text { VAS }\end{array}$ & Mean & $\mathbf{P}$ \\
\hline $5 \min$ & $3,7,4,3,2,1,0$ & 2.8 & - & $0,0,0,0,0,0,0$ & 0.0 & - \\
\hline $15 \mathrm{~min}$ & $5,9,7,8,7,6,6$ & 6.9 & 0.02 & $0,5,2,0,0,0,0$ & 1.0 & 0.19 \\
\hline $30 \mathrm{~min}$ & $5,8,5,5,6,8,8$ & 6.4 & 0.02 & $3,7,2,2,0,2,0$ & 2.6 & 0.04 \\
\hline $1 \mathrm{~h}$ & $4,6,3,2,4,7,6$ & 4.6 & 0.30 & $7,7,4,7,0,3,0$ & 4.0 & 0.04 \\
\hline $1.5 \mathrm{~h}$ & $0,2,0,0,1,6,4$ & 1.9 & 0.67 & $3,7,5,3,2,2,0$ & 3.1 & .03 \\
\hline $2 \mathrm{~h}$ & $0,1,0,0,1,4,2$ & 1.1 & 0.20 & $1,7,8,2,2,0,0$ & 2.9 & 0.04 \\
\hline $3 \mathrm{~h}$ & $0,0,0,0,0,1,0$ & 0.0 & 0.04 & $0,7,6,2,2,0,0$ & 2.2 & 0.07 \\
\hline $4 \mathrm{~h}$ & $0,0,0,0,0,0,0$ & 0.0 & 0.03 & $0,5,2,1,0,0,0$ & 1.1 & 0.11 \\
\hline
\end{tabular}

${ }^{*}$ compared with the score at 5 min; VAS Visual analog scale 
possible that in patients with severe mucosal pain, higher concentrations of drug may be beneficial, and may not be associated with fatigue to the degree seen in normal volunteers. It is possible that the duration of rinsing in the subjects without mucosal lesions was longer and was associated with increased tiredness and fatigue more than in the cancer patients.

Both of the trials of doxepin rinse (11) examined a single dose of topical doxepin, and experience with systemic dosing of TCAs suggests a reduction in sedation with continued use over time. Consistent with sedation reported with systemic use, several of the cancer patients who reported sedation with topical rinsing in this study continued use due to the significant analgesic effect and reported reduction in fatigue with continuing use. We concluded that the results of the trial in cancer patients showed that topical doxepin rinse provided clinically significant pain relief in patients with mucosal damage

\section{REFERENCES}

1. Tollison CD, Kriegel ML. Selected tricyclic antidepressants in the management of chronic benign pain. South Med J 1988;81:562-4.

2. Medical Economics Comany, Hogan RW. The Pdr Family Guide to Prescription Drugs. New York: Three Rivers Press, 1998.

3. Hameroff SR, Cork RC, Scherer K, et al. Doxepin effects on chronic pain, depression and plasma opioids. J Clin Psychiatry 1982;43:22-7.

4. Kiefer G, Fischer W, Feuerstein TJ. Effects of amitriptyline, amitriptylinoxide, doxepin and clozapine on N-methyl-D-aspartateevoked release of $(3 \mathrm{H})$-acetylcholine in rat caudatoputamen. Arzneimittelforschung 1999;49:820-3.

5. McCleane G. Topical application of doxepin hydrochloride, capsaicin and a combination of both produces analgesia in chronic human neuropathic pain: A randomized, double-blind, placebocontrolled study. Br J Clin Pharmacol 2000;49:574-9.

6. Richeimer SH, Bajwa ZH, Kahraman SS, Ransil BJ, Warfield CA. Utilization patterns of tricyclic antidepressants in a multidisciplinary pain clinic: A survey. Clin J Pain 1997;13:324-9.

7. Cohn ML, Machado AF, Bier R, Cohn M. Piroxicam and doxepin an alternative to narcotic analgesics in managing advanced cancer pain. West J Med 1988;148:303-6.

8. Salem RB, Fischer RG, Beghe C. Acute stomatitis associated with doxepin therapy. Drug Intell Clin Pharm 1981;15:992-3.

9. McLean GJ. Topical doxepin hydrochloride reduces neuropathic pain: A randomized, double-blind, placebo controlled study. The Pain Clinic 2000;2:47-50. and had an excellent profile of duration of effect, allowing a convenient dosing schedule.

Topical medications may reduce mucosal pain, providing pain relief while allowing a reduction in the use of systemic analgesics, including opioids. The results of our two open-label trials suggest that the doxepin rinse may be a useful medication when applied topically to damaged oral mucosa, and that the pain effect is due to an early anesthetic effect, followed by an analgesic effect. The rapid onset and duration of pain relief, and lack of burning with use, even in patients with damaged mucosa, are desirable qualities. If drowsiness occurs, use of the agent may be indicated at night, and in settings where the patient is not operating machinery or driving. Further dose ranging studies will allow for a better determination of the frequency of drowsiness and the concentration needed for the optimum analgesic effect.

10. Sonis ST, Eilers JP, Epstein JB, et al. Validation of a new scoring system for the assessment of clinical trial research of oral mucositis induced by radiation or chemotherapy. Cancer 1999;85:2103-13.

11. Epstein JB, Truelove EL, Oien H, Allison C, Epstein MS. Oral topical doxepin rinse: Analgesic effect in patients with oral mucosal pain due to cancer or cancer therapy. Oral Oncol 2001;37:632-7.

12. Epstein JB, Schubert MM. Management of orofacial pain in cancer patients. Eur J Cancer Oral Oncol 1993;29B:243-50.

13. Kramp LF, Eleazer PD, Scheetz JP. Evaluation of prilocaine for the reduction of pain associated with transmucosal anesthetic administration. Anesth Prog 1999;46:52-5.

14. Ameer B, Burlingame MB, Harman EM. Rapid mucosal absorption of topical lidocaine during bronchoscopy in the presence of oral candidiasis. Chest 1989;96:1438-9.

15. Elad S, Cohen G, Zylber-Katz E, et al. Systemic absorption of lidocaine after topical application for the treatment of oral mucositis in bone marrow transplantation patients. J Oral Pathol Med 1999;28:170-2.

16. Epstein JB, Stevenson-Moore P, Jackson SM, Mohamed JH, Spinelli JJ. Prevention of oral mucositis in radiation therapy: A controlled study with benzydamine hydrochloride rinse. Int J Radiat Oncol Biol Phys 1989;16:1571-5.

17. Berberian BJ, Breneman DL, Drake LA, et al. The addition of topical doxepin to corticosteroid therapy: An improved treatment regimen for atopic dermatitis. Int J Dermatol 1999;38:145-8. 


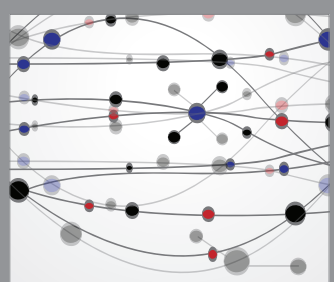

The Scientific World Journal
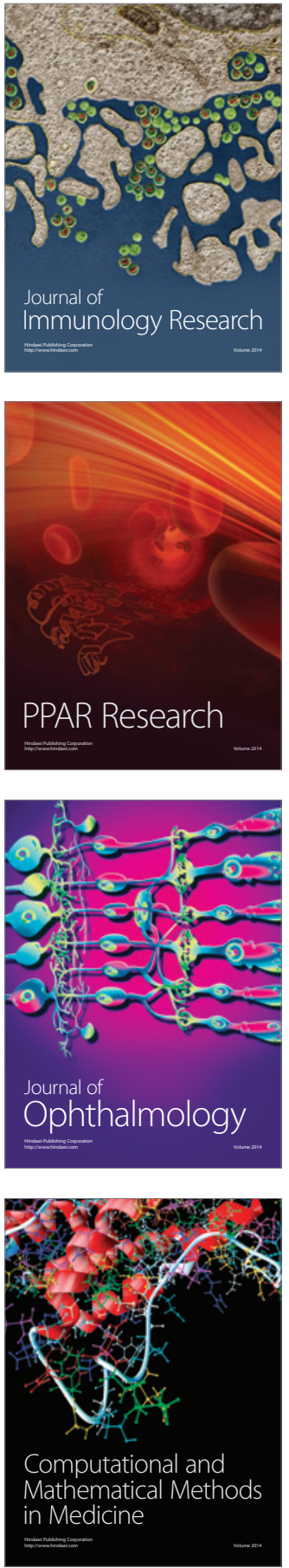

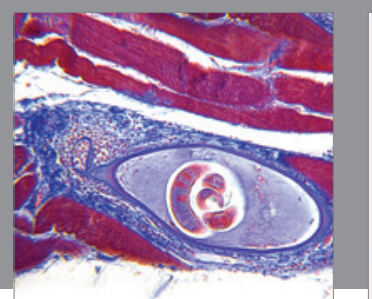

Gastroenterology Research and Practice

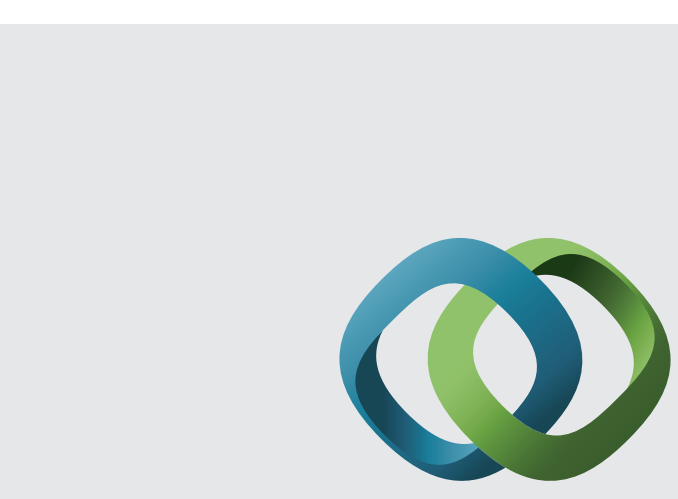

\section{Hindawi}

Submit your manuscripts at

http://www.hindawi.com
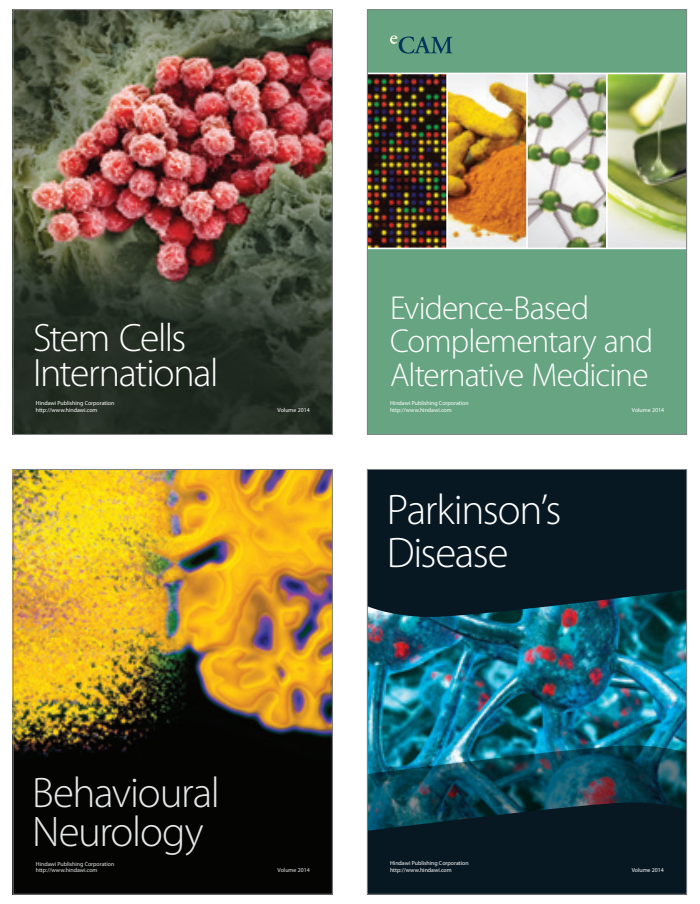
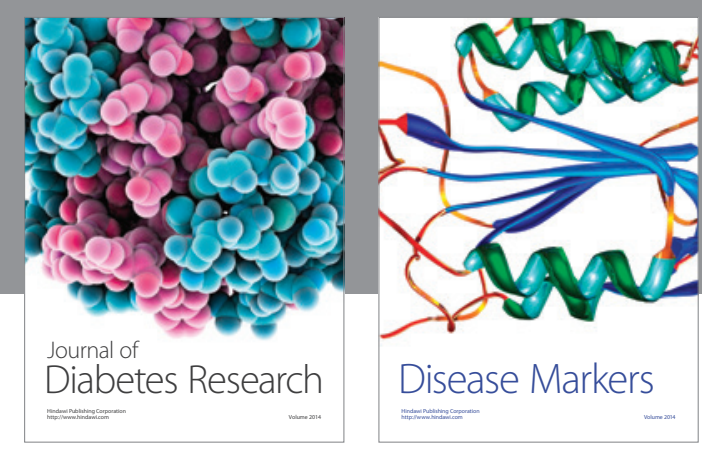

Disease Markers
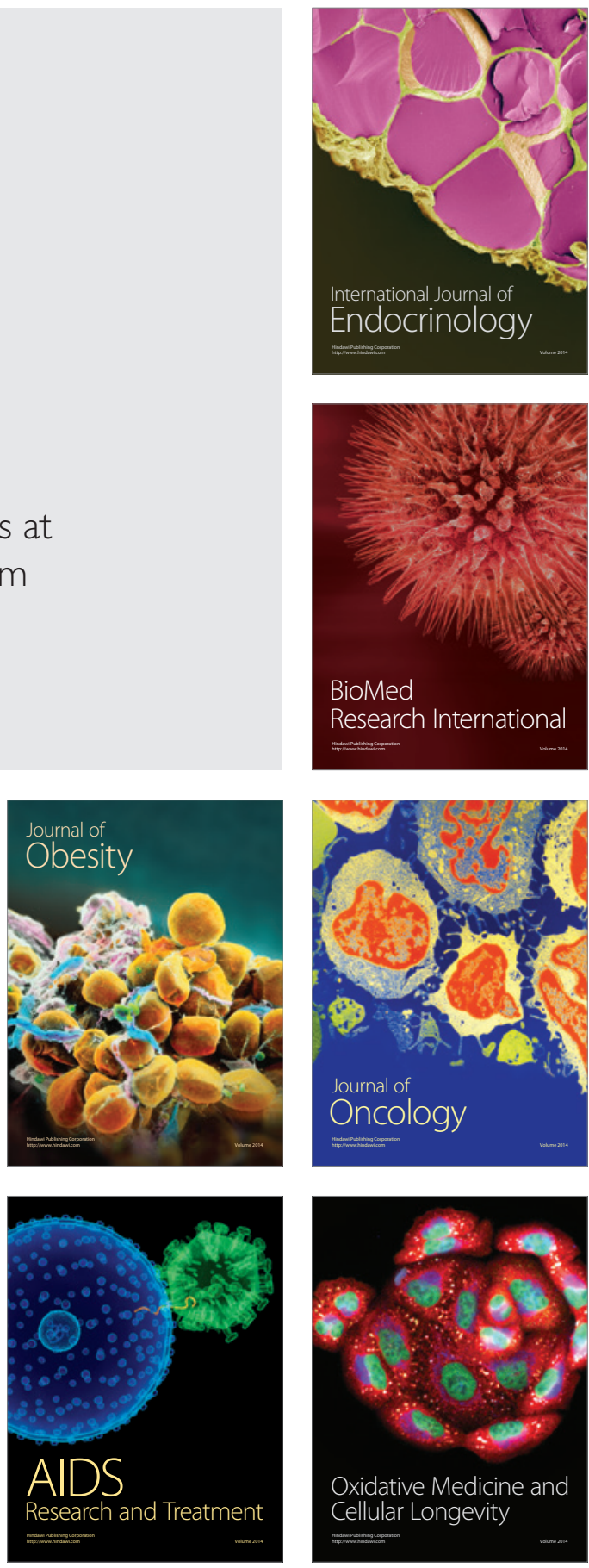